\title{
Preparation and Evaluation of Multi-Particulate System (Pellets) of Prasugrel Hydrochloride
}

\author{
Navjot Kanwar, Rakesh Kumar and V.R. Sinha*
}

UIPS, Panjab University, Chandigarh 160014, India

\begin{abstract}
Multiparticulate systems (pellets) of prasugrel hydrochloride were prepared by extrusion spheronization method using MCC (micro crystalline cellulose). Optimum spheronization time and method of drying were selected as the process parameters for the preparation of final batches. Various pellet properties were evaluated like size \& shape analysis, flow properties, bulk \& tapped density, friability, moisture content, drug content, in vitro release rate and in vivo pharmacodynamic studies. All pellet batches showed a narrow particle size distribution, good sphericity and excellent flow properties. Drug content and moisture content of different pellet batches were found in specified limits. The release kinetics of drug loaded MCC pellets followed Peppas model with Fickian diffusion of prasugrel from the pellets. In vivo pharmacodynamic studies exhibited improved bleeding time in pellet group when compared with the marketed tablet formulation.
\end{abstract}

Keywords: Carr index, Hausner ratio, MCC pellets, Microwave oven drying, Prasugrel hydrochloride.

\section{INTRODUCTION}

Multiparticulate drug delivery systems (like pellets, granules, etc.) provide better gastrointestinal distribution and transportation resulting in minimizing the peak plasma fluctuations and side effects related to drug which are major advantages over single unit systems. Also, these delivery systems facilitate co-administration of incompatible drugs (using coated pellets) [1-3].

Pellets are oral dosage forms which are spherical beads with a mean particle size between 0.5 to $2 \mathrm{~mm}$. Pellets are pharmaceutical formulations in which the active pharmaceutical ingredient is present as a number of small discrete units, each exhibiting some desired characteristics [4].

Pellets provide flexibility of delivery system, i.e. either be filled in capsules or compressed into tablets. Other advantages include lower irritative effects due to decreased local concentration and lower the risk effect due to dose dumping [5-8]. Pellets reduce the intra- and inter-subject variability in drug concentration by reducing the gastric emptying rate and transit time [9].

Extrusion-spheronisation is one of the most common and widely accepted methods for preparation of pellets in pharmaceutical technology $[10,11]$. It is a multi-step process which produces pellets of good physical strength, uniform diameter and good porosity. The main advantage of pellets prepared by extrusion-spheronization method over other methods is the ability to incorporate high levels of active ingredient without producing excessively large particles $[12,13]$.

*Address correspondence to this author at the UIPS, Panjab University, Chandigarh 160014, India; Tel: +91 172 2534101; Fax: +91 172 2543101; E-mail: sinha_vr@rediffmail.com
Prasugrel hydrochloride is a prodrug and a potent platelet inhibitor. It is an oral thienopyridine with rapid onset of action, consistent antiplatelet activity and prolonged duration of effect. It is used for reducing thrombotic cardiovascular events in patients with acute coronary syndromes managed with percutaneous coronary intervention [14].

In the present study, the effect of various process parameters (extrusion speed and spheronisation time) and drying methods (oven, vacuum oven and microwave oven) used in the preparation of prasugrel hydrochloride pellets (using extrusion-spheronisation method) were analyzed.

\section{MATERIALS AND METHODS}

\subsection{Materials}

Prasugrel hydrochloride was a generous gift from MSN Laboratories Limited, Bollaram, India. Avicel grade (MCC) was obtained from Ankit Pulps and Pvt. Ltd. All other chemicals and reagents used were of analytical grade.

\subsection{Preparation of Pellets}

Pellets were prepared using ethyl alcohol (absolute alcohol and with 5\% water), propyl alcohol and distilled water as granulating liquid. Amount of granulating liquid $(40 \mathrm{~mL})$ used for preparation of pellets was taken as constant. Powder mass $(100 \mathrm{gm})$ was moistened with $40 \mathrm{~mL}$ of the granulating fluid and extruded through the extruder with sieve no. 8\# at 3 $\mathrm{rpm}$ and then spheronized in a spheronizer at $1000 \mathrm{rpm}$ for 3 min. Extruder 25 and spheronizer 120 manufactured by Caleva process solution limited were used for pellet preparation. Effect of operational parameters, i.e. spheronization time and method of drying were studied on pellet properties. Optimum parameters were selected for the preparation of final batches of pellets. Extruder speed was kept constant. 
Wet pellets thus obtained were dried in the microwave for 2 min. Batch $\mathrm{F}$ and $\mathrm{G}$ differed in drug loading. Batch $\mathrm{F}$ contained $2 \% \mathrm{w} / \mathrm{w}$ drug whereas batch $\mathrm{G}$ contained $1 \% \mathrm{w} / \mathrm{w}$ drug.

The amount of granulating liquid used was kept constant for all the batches. $100 \mathrm{~g}$ powder mixture was taken and the dough was prepared using $40 \mathrm{~mL}$ water as granulating liquid. No other excipient was used for pellet formation. This wet mass was then extruded through the extruder at constant speed and subsequently spheronised on a spheroniser at a specific speed and time. Wet pellets thus obtained were dried with the help of microwave oven for $2 \mathrm{~min}$.

\subsection{Characterization of Pellets}

\subsubsection{Size Analysis}

Size analysis of the pellet batches was carried out by Malvern Mastersizer 2000 (Malvern Instruments Ltd, Worcestershire, UK.). Pellets, which passed through 16\# sieve, but retained on $25 \#$ sieve were taken for size analysis.

\subsubsection{Shape Analysis}

At least 20 pellets from each batch were randomly selected from the fraction obtained from size analysis. Pellets were mounted on a light microscope fitted with a camera and images of pellets were taken. Maximum and minimum radii of pellets were determined after measuring their respective diameters. Using these radii various shape factors were calculated as given below:

$$
\begin{aligned}
& \text { Roundness }=\text { Area } / 4 \pi(\text { maximum radius })^{2} \\
& \text { Elongation }=\text { Maximum radius } / \text { Minimum radius } \\
& \text { Pellips }=4 \times \text { Perimeter } / 2 \pi(\text { maximum radius })^{2} \\
& \text { Rectang }=\text { Area } / 4 \text { (maximum radius } x \text { minimum radius) }
\end{aligned}
$$

\subsubsection{Bulk and Tapped Density}

Pellets were poured gently through a glass funnel into a $50 \mathrm{~mL}$ graduated cylinder until pellets just touched the 50 $\mathrm{mL}$ mark and the weight of cylinder required for filling the cylinder volume was determined. The cylinder was then tapped from the height of $2 \mathrm{~cm}$ until there was no more volume change. Bulk density was calculated as the quotient of the weight of pellets and volume of cylinder used. Tapped density was calculated as the quotient of the weight of the pellets and its volume after tapping.

\subsubsection{Carr's Index and Hausner Ratio}

Using bulk and tapped densities Carr's index (IC) and Hausner ratio (HR) was determined using formulae given below:

$$
\begin{aligned}
& \mathrm{HR}=\text { Tapped density/Bulk density } \\
& \mathrm{IC}=\text { Tapped density-Bulk density/Tapped density }
\end{aligned}
$$

\subsubsection{Flow Rate}

The flow rate was calculated as the time taken for $10 \mathrm{~g}$ of pellets to flow through a funnel of $5 \mathrm{~mm}$ internal diameter. All the determinations were repeated in triplicate and the average flow rate with standard deviation was expressed in $\mathrm{g} / \mathrm{sec}$.

\subsubsection{Angle of Repose}

Angle of repose is a measure of flow properties of powder or pellets. The pellets were poured gently through a funnel, which was fixed at a position such that its lower tip was at the height exactly $2 \mathrm{~cm}$ above a hard surface. The pellets were poured until the upper tip of the pile surface touched the lower tip of the funnel. The $\tan ^{-1}$ of (height of the pile/radius of its base) gave the angle of repose.

\subsubsection{Friability}

Accurately weighed $(5 \mathrm{~g})$ pellets were taken and placed in Roche's friabilator and rotated for 200 revolutions at 25 $\mathrm{rpm}$. Twelve steel balls (diameter $6.3 \mathrm{~mm}$, weighing 1.028 gm each) were used to provide attrition. After friability, pellets were sieved through sieves. The weight loss $(\% \mathrm{~F})$ after friability testing was calculated by the formula given below

$\%$ Friability $=($ Initial weight-Final weight/Initial weight $)$ $\mathrm{x} 100$

\subsubsection{Moisture Content}

The sample $(5 \mathrm{~g})$ was placed in the infra-red moisture balance and heated using infra-red lamp. After complete removal of water present in the samples, the percentage moisture content was obtained from the instrument.

\subsubsection{Drug Content}

A known weight $(500 \mathrm{mg})$ of the powdered pellets was dispersed in $100 \mathrm{~mL}$ of methanol. This was further diluted 10 times and filtered. The drug in the solution was analyzed using UV-visible spectrophotometer at $\lambda_{\max }$ of $254 \mathrm{~nm}$. All the determinations were done in triplicate. The drug has an appreciable solubility in methanol.

\subsubsection{Dissolution Studies}

A sieve fraction of the pellets which pass through $16 \#$ but retained on $30 \#$ were used to study the drug release. $500 \mathrm{mg}$ of the pellets having particle size 779.12-866.21 $\mu \mathrm{m}$ were used for dissolution studies. $500 \mathrm{mg}$ pellets were equivalent to $10 \mathrm{mg}$ and $5 \mathrm{mg}$ of drug in batch $\mathrm{F}$ and $\mathrm{G}$ respectively.USP dissolution apparatus type 2 was used at a speed of $75 \mathrm{rpm}$. Aqueous solution containing 1\% SLS was used as dissolution medium. Samples were taken at different time intervals and analyzed using UV spectrophotometry at $\lambda_{\max }$ of $254 \mathrm{~nm}$. The same volume of fresh aqueous solution containing $1 \%$ SLS was replaced in dissolution beaker. Dissolution studies were performed in triplicate and average drug release with standard deviation was calculated.

\subsubsection{In Vivo Pharmacodynamic Studies}

Prasugrel hydrochloride, an anti-platelet drug was used to calculate the bleeding time in animals. The test was performed using male SD rats weighing 120-210 g. The animals were housed in accordance with the guidelines of institutional animal care and use committee (IACUC). All the animals were acclimatized to the laboratory conditions before use and feed on a standard normal pellet diet and water. Animals were divided into 3 groups, i.e. Group I was taken as a control, Group II was treated with pellets formulation and Group III was treated with marketed formulation. 


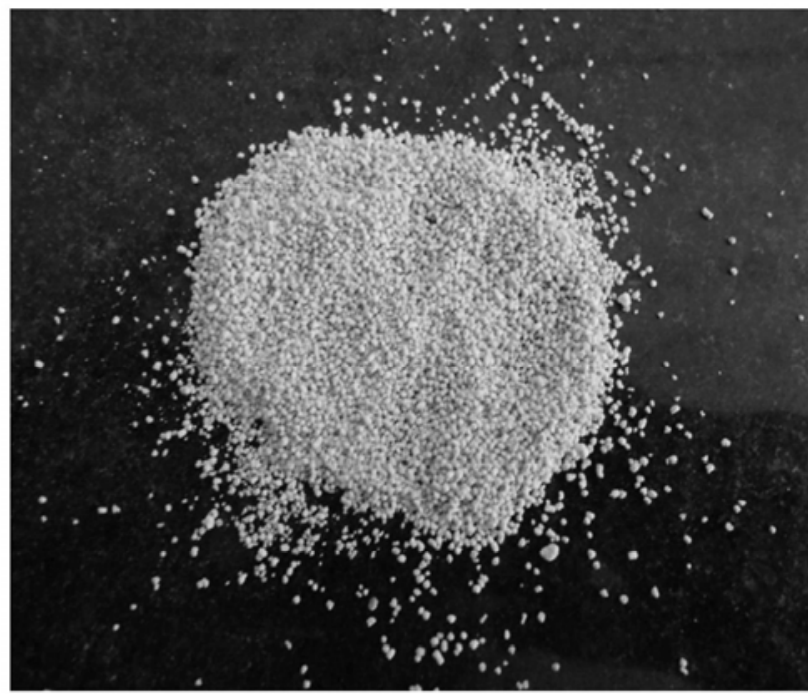

(a)

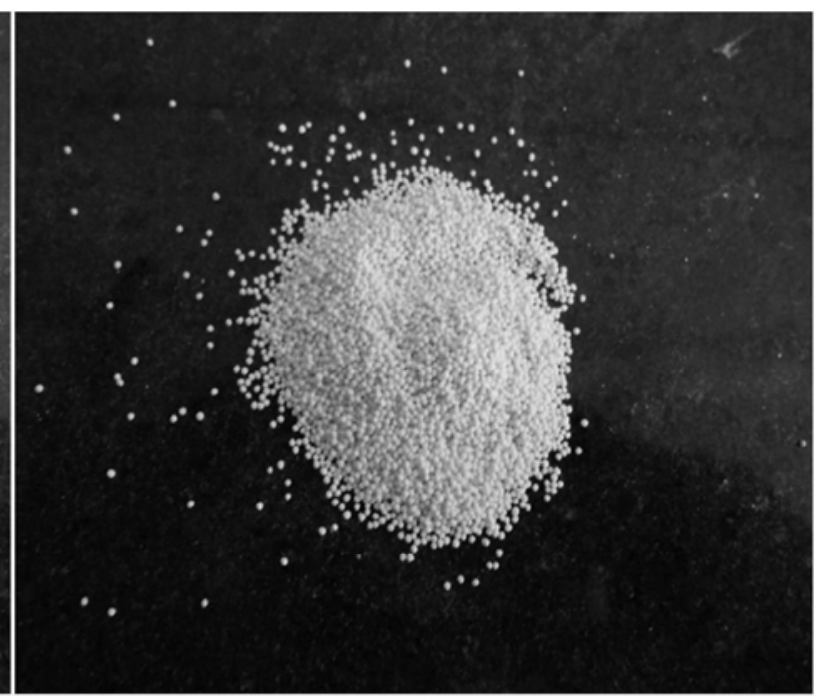

(b)

Fig. (1). Drug loaded MCC pellets (Batch F) using water as granulating agent and dried in (a) oven at $40^{\circ} \mathrm{C}$ for 15 min (b) microwave for 3 $\min$.

Male SD rats were fasted overnight before the experiment. After one hour of the treatment with the test formulations (Pellets and marketed tablets), Ketamine $(75 \mathrm{mg} / \mathrm{kg}$ ) was given i.p. to anesthetize the rats. The tail was transected $3 \mathrm{~mm}$ from its tip with a razor blade and then immersed in a $15 \mathrm{~mL}$ clear conical tube containing normal saline prewarmed to $37^{\circ} \mathrm{C}$. Time for blood flow cessation (defined as no bleeding for $15 \mathrm{sec}$ ) was measured [15].

\subsubsection{Statistical Analysis}

Simple analysis of variance (one-way ANOVA, GraphPad Prism 5) was used to determine statistically significant differences between the results and values with $\mathrm{p}<0.05$ were considered statistically significant.

\section{RESULTS AND DISCUSSION}

\subsection{Preparation of Pellets}

\subsubsection{Granulating Agent}

Non-aqueous vehicle (Alcohol): When absolute alcohol was used as granulating fluid, pellets formation failed that might be due to the lack of swelling of MCC (in the presence of ethyl alcohol). Similar results observed when isopropyl alcohol was used as granulating liquid. However, ethyl alcohol containing 5\% water led to the formation of pellets, but on drying pellets crumbled due to lack of cohesion [16].

Aqueous vehicle (Water): MCC pellets were successfully formed using water as granulating liquid. However, pellets developed brown coloration when dried in oven at $40^{\circ} \mathrm{C}$ (Fig. 1). Hence, water is considered as the choice of granulationg fluid over ethyl alcohol and isopropyl alcohol in preparation of MCC pellets.

\subsubsection{Drying Methods}

It could be concluded that the discoloration (brown coloration) of pellets might have developed due to drying method (prolonged heating in the oven). Hence, different drying methods were used to prevent discoloration of pellets.
Vaccum oven: Drug loaded MCC pellets were prepared using water as granulating fluid and dried in vacuum oven at $5^{\circ} \mathrm{C}$ and $15 \mathrm{~mm} \mathrm{Hg}$. However, brown coloration of pellets was also observed under these conditions.

Microwave oven: No change in aesthetic properties of pellets were observed when dried in a microwave oven (Fig. 1). Unlike conventional oven, miro-oven utilizes micrwave radiations for drying and the duration of exposure was also lower which allowed complete drying of pellets without affecting any physio-chemical properties.

Based on the above observations, drug loaded MCC pellets using water as granulating fluid and microwave oven as drying method was selected as the optimized batch (Table 1).

\subsection{Evaluation of Pellets}

\subsubsection{Size Analysis}

Size distribution of pellets is an important characteristic as it affects the release kinetics of pellets [17]. Narrow particle size distribution is an indicator of uniformity in particle size. Polydispersity i.e. width of particle size distribution is measured by span. Span value less than 1.5 indicates narrow particle size distribution. The large span value indicates the variation in particle size, which results in segregation and non-uniform coating of pellets [18]. Arithmetic and geometric mean diameter are parameters for determining the size of pellets.

Particle size distribution curves were obtained from Malvern microsizer 2000 by dry method. Bell-shaped curves were obtained showing normal distribution, i.e. Gaussian curve. Mean diameter of pellets $\mathrm{d}(0.5)$ range from $779.12 \mu \mathrm{m}$ (batch F) to $866.21 \mu \mathrm{m}$ (batch G) as shown while the Span value of different pellet batches was found to be 0.68 and 0.73 for batch $F$ and $G$, respectively. Span value for all the pellet batches was found to be less than 1.5 which indicated narrow particle size distribution. 
Table 1. Different granulating fluids and drying methods used for pellet preparation.

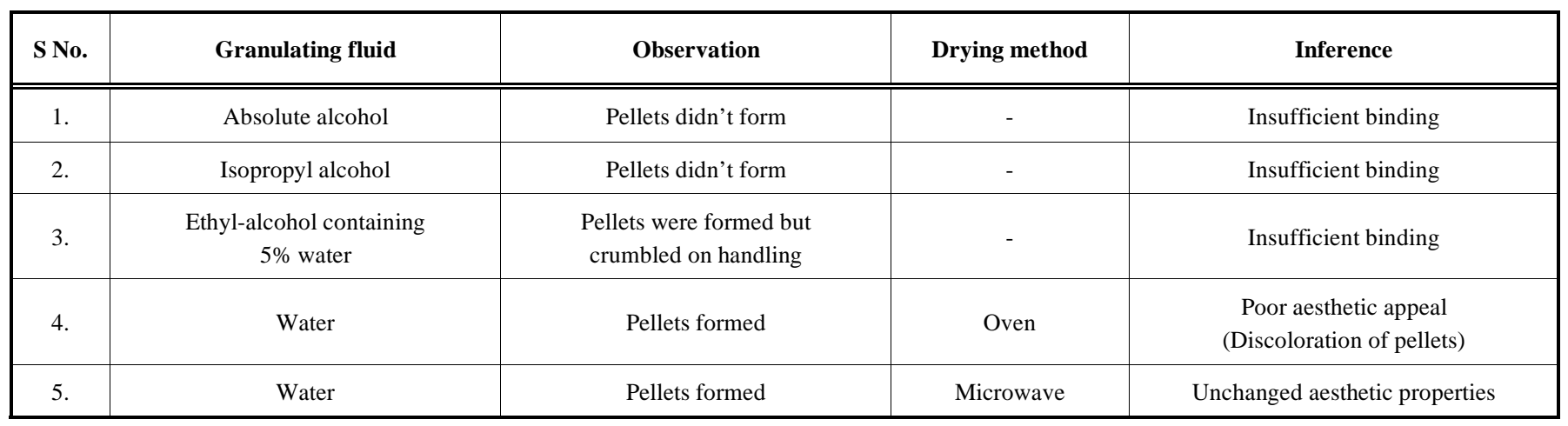

\subsubsection{Shape Analysis}

Roundness of pellet batches $F$ and $G$ was found as $0.92 \pm 0.05$ and $0.92 \pm 0.04$, respectively, which confirms the good sphericity of pellets as shown in Fig. (2). Roundness or sphericity enhances the uniformity of pellet shape that facilitates uniform/smooth coating of pellets. Higher value of Pellips and elongation indicates lower sphericity of pellets [19]. Elongation of pellet batches $\mathrm{F}$ and $\mathrm{G}$ was found as $1.09 \pm 0.06$ and $1.09 \pm 0.04$, respectively. Pellips and rectang values for pellet batches $\mathrm{F}$ and $\mathrm{G}$ were found to be $0.002 \pm 0.0003 \&$ $0.002 \pm 0.0002$, and $0.78 \pm 0.01 \& 0.79 \pm 0.02$, respectively.

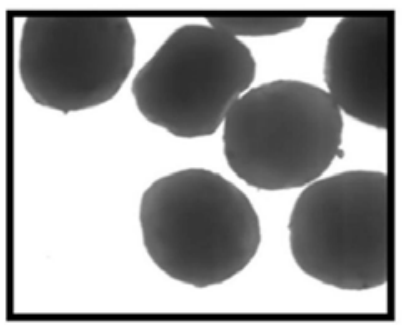

BATCH F

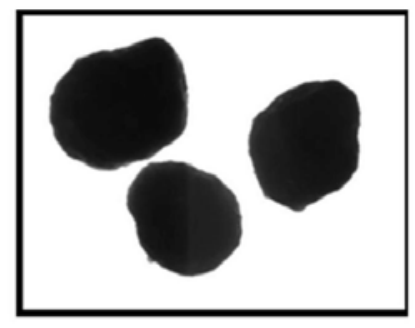

BATCH G
Fig. (2). Microscopic evaluation of pellet batches F and G (magnification $10 \mathrm{X})$.

Experiments were performed in the present studies to describe the mechanism of spheronization and the effect of spheronization time on shape of pellets after 2, 3 and 5 min. Initially, after extrusion the shape of extrudes was elongated which became dumb-bell shape after spheronizing the extrudes for $2 \mathrm{~min}$. However, spherical pellets were formed after a spheronization period of 3 to $5 \mathrm{~min}$ as shown in Fig. (3). Hence, the sphericity of the pellets increased with spheronization time but no further changes in the roundness of pellets were observed after $5 \mathrm{~min}$. Hence, the optimum spheronization time was selected as $5 \mathrm{~min}$. The increase in roundness/sphericity with spheronization time could be explained by the fact that the extrudes were exposed to attrition forces for a longer period that resulted in improved sphericity. But after an optimum time period $(5 \mathrm{~min})$, pellets become rigid enough so that attrition forces have no further significant impact on the shape of pellets [20].

\subsubsection{Bulk and Tapped Density}

Tapped and bulk density for pellet batches were found as $0.57 \& 0.69 \mathrm{~g} / \mathrm{cm}^{3}$ (batch F) and $0.56 \mathrm{~g} / \mathrm{cm}^{3} \& 0.69 \mathrm{~g} / \mathrm{cm}^{3}$ (batch G). Carr index and Hausner ratio for both the batches (F \& G) were found as 1.30 and $1.01 \%$ respectively. On comparing the values of Carr index and Hausner ratio given in USP 2011 with the experimental outcome, it was found that the flow properties of all batches were excellent.

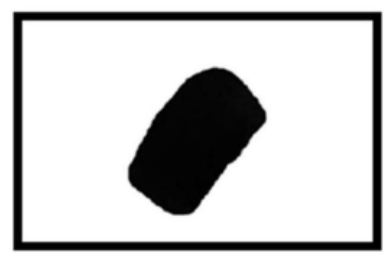

0 min.

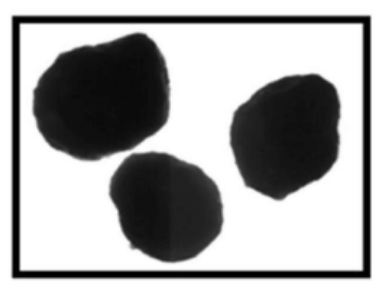

$3 \mathrm{~min}$.

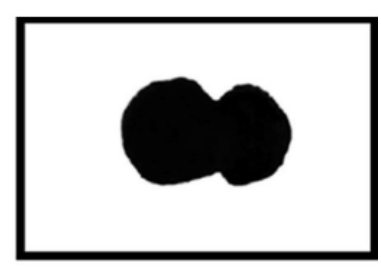

$2 \min$.

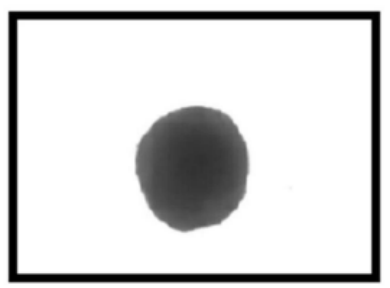

$5 \mathrm{~min}$.
Fig. (3). Photomicrographs of extrudes [without spheronization $(0$ $\mathrm{min}$ ), after $1 \mathrm{~min}$ (dumb-bell shaped), $3 \mathrm{~min}$ and $5 \mathrm{~min}$ of spheronization] (magnification 10X).

\subsubsection{Flow Properties of Pellet Batches}

Pellets with high spheronization time showed good flow properties as compared to pellets with the low spheronization time that could be attributed to the improved sphericity of pellets with increasing spheronization time. The angle of repose for pellets batch $F$ and $G$ was $28.10 \pm 1.42^{\circ}$ and $30.36 \pm 0.23^{\circ}$ respectively. Similarly, the flow rate of pellet batches $F$ and $G$ was found as $2.82 \pm 0.24$ and $2.64 \pm 0.09$ $\mathrm{g} / \mathrm{sec}$, respectively. These values indicated an excellent flow of pellet batches.

\subsubsection{Friability of Pellet Batches}

Friability of pellets helps in determining the hardness and strength of pellets. MCC pellets produced by extrusion spheronization method have low friability. The friability of pellet batches $\mathrm{F}$ and $\mathrm{G}$ was found to be $1.80 \%$ and $0.60 \%$ respectively. 


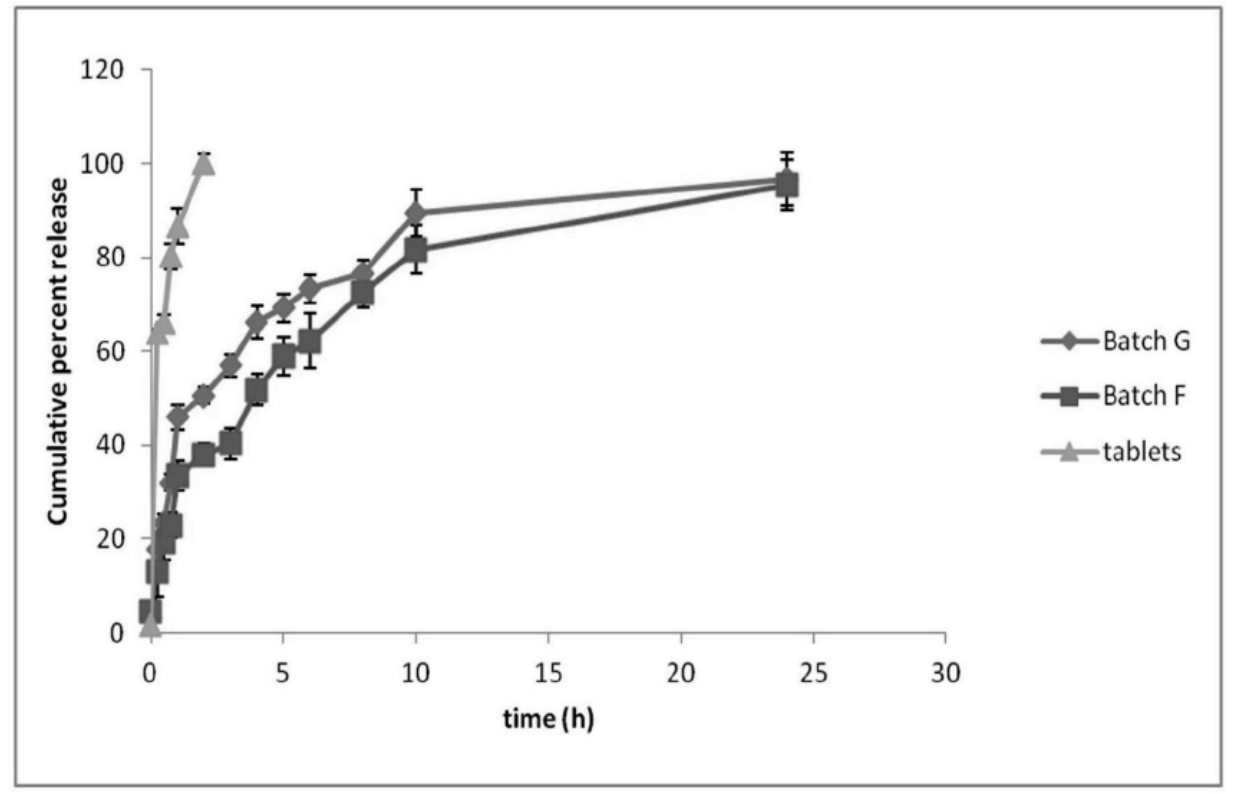

Fig. (4). In-vitro release of prasugrel $\mathrm{HCl}$ from pellets.

Table 2. Prasugrel release kinetics from selected batches.

\begin{tabular}{|c|c|c|c|c|c|c|c|c|c|}
\hline \multirow{2}{*}{$\begin{array}{c}\text { Kinetic model } \\
\text { Batch }\end{array}$} & \multicolumn{2}{|c|}{$\begin{array}{c}\text { Zero order } \\
D_{t}=D_{0}+K_{0} t\end{array}$} & \multicolumn{2}{|c|}{$\begin{array}{c}\text { First order } \\
\ln D_{t}=\ln D_{0}+K_{1} t\end{array}$} & \multicolumn{2}{|c|}{$\begin{array}{c}\text { Higuchi } \\
D_{t}=D_{0}+K_{H} t^{1 / 2}\end{array}$} & \multicolumn{3}{|c|}{$\begin{array}{c}\text { Korsemeyer-Peppas } \\
\qquad \mathbf{D}_{\mathbf{t}} / \mathbf{D}_{\infty}=\mathbf{K}_{\mathrm{P}} \mathbf{t}^{\mathrm{n}}\end{array}$} \\
\hline & $\mathrm{R}^{2}$ & $\mathrm{~K}_{0}$ & $\mathrm{R}^{2}$ & $\mathrm{~K}_{1}$ & $\mathrm{R}^{2}$ & $\mathrm{~K}_{\mathrm{H}}$ & $\mathrm{R}^{2}$ & $\mathrm{~K}_{\mathrm{P}}$ & $\mathrm{n}$ \\
\hline $\mathrm{F}$ & 0.61 & 3.43 & 0.94 & 0.139 & 0.89 & 20.3 & 0.98 & 0.38 & 0.28 \\
\hline $\mathrm{G}$ & 0.74 & 3.66 & 0.96 & 0.127 & 0.94 & 20.02 & 0.97 & 0.45 & 0.22 \\
\hline
\end{tabular}

where $D_{t}$ is the amount of drug released at time $t, D_{0}$ is the initial amount of drug released, $D_{t} / D_{\infty}$ is fraction of drug released at time $t, k_{0}$ is the zero-order release constant, $k_{1}$ is the first-order release constant, $\mathrm{k}_{\mathrm{H}}$ is the Higuchi release constant, $\mathrm{K}_{\mathrm{P}}$ is the Peppas release constant, and $\mathrm{n}$ is the release exponent.

\subsubsection{Moisture Content of Pellet Batches}

The moisture content of prasugrel pellet batches was found close to $2 \%$, which was within the prescribed limit. Moisture content is a parameter to evaluate the quality of the pellets. Moisture content below $1 \%$ indicates high friability of pellets (i.e. pellets break easily upon crushing) while higher moisture content $(>3 \%)$ increases stickiness of pellets.

\subsubsection{Drug Content of Pellet Batches}

Drug content of pellets batch $\mathrm{F}$ and $\mathrm{G}$ was found between $97.28 \pm 0.10 \%$ and $98.53 \pm 1.92 \%$ respectively.

\subsubsection{In Vitro Release Studies of Pellets}

Batch $F$ and $G$ showed a burst release of $37.96 \pm 2.31$ and $50.61 \pm 1.77 \%$ respectively in first two hours while sustained release was observed for the batch $\mathrm{F}(95.54 \pm 5.32 \%)$ and $\mathrm{G}$ $(96.70 \pm 5.73 \%)$ after $24 \mathrm{hr}$ (Fig. 4). No significant difference ( $>0.05$ ) was observed between the release profile of batches $\mathrm{F}$ and $\mathrm{G}$. The release data of batch $\mathrm{F}$ and $\mathrm{G}$ was fitted to different kinetic models, viz. zero order, first order, Higuchi model and Korsmeyer-Peppas model. Among the kinetic models employed, Korsemeyer-Peppas showed a better fit as the $\mathrm{R}^{2}$ value was comparatively higher than the other kinetic models (Table 2). According to Peppas equation drug release from formulation occurs by diffusion of the drug from the formulation. The mechanism of diffusion deviates from the
Fickian equation and follows a Non-Fickian or anomalous (irregular) behaviour in many cases, including the case of drug release from swellable polymeric systems. The values of release exponent, $\mathrm{n}$ observed using Peppas model was found as 0.28 and 0.22 for batch $F$ and $G$, respectively suggesting Fickian diffusion of prasugrel from the pellets. In general the values of $n \leq 0.5,0.5-1$ and $\geq 1$ are related to Fickian diffusion (case I transport), anomalous, and case II transport (zero order release), respectively [21-23]. Unlike optimized pellet batches, marketed formulation (tablet) exhibited immediate release $(100.07 \pm 2.06 \%$ in $2 \mathrm{hr})$.

As batch $\mathrm{F}$ has the lower burst release with sustained release profile, it was selected as the optimized batch for further studies.

\subsubsection{In Vivo Pharmacodynamic Studies}

Bleeding time provides a useful mean for estimation of platelet function. It helps in studying the in vivo effect of drugs which interfere with platelet aggregation [15]. In vivo pharmacodynamic efficacy of prepared formulation was evaluated and compared with marketed formulation (Prasita 10 mg-Tablet, Ranbaxy, Gurgaon, India). Bleeding test was performed to estimate the pharmacodynamic efficacy of different formulations. Animals were divided into three groups: Group I was taken as control Group, Group II was treated with pellets (batch $\mathrm{F}$ ) suspended in $1 \% \mathrm{w} / \mathrm{v}$ 


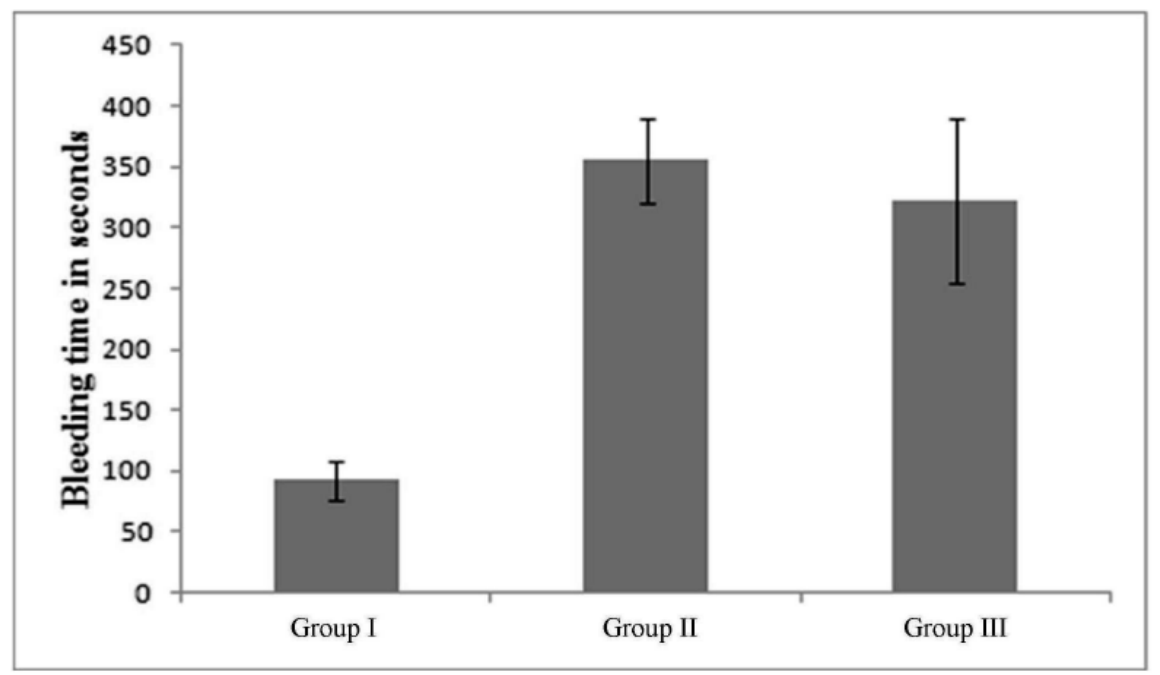

Fig. (5). Comparison of bleeding time in animal groups.

methylcellulose and Group III was treated with marketed formulation. In Group I, after administrating $1 \%$ w/v methylcellulose suspension, a cut was made on the tail after $1 \mathrm{~h}$. The group I showed the bleeding time of $92.50 \pm 15.90 \mathrm{sec}$ (Fig. 5) and was considered as the normal bleeding time in rats. Similarly, pellets suspended in $1 \% \mathrm{w} / \mathrm{v}$ methylcellulose and the marketed tablet were orally administered to the animals of group II and III respectively, and the bleeding time was noted as $355.00 \mathrm{sec}$ (group II) and $321.75 \mathrm{sec}$ (group III). It was found that pellets (Group II) significantly prolonged the bleeding time as compared to control group (Group I) and marketed formulation (Group III). The increased bleeding time in pellet formulation as compared to tablet might be due to the increased bioavailability (as a result of sustained drug release) of the drug resulted in improved therapeutic efficacy.

\section{CONCLUSION}

The multi-unit particulate system (pellets) of prasugrel hydrochloride was successfully developed and characterized. The extrusion-spheronization and the microwave oven used for fabrication and drying of pellets respectively, helped in the development of optimized pellet batches. The optimized formulation (Batch F) displayed narrow size distribution, good sphericity, low friability, higher drug content with a sustained release profile. Apart, the optimized batch exhibited improved therapeutic activity when compared with the marketed formulation. Further, incorporating the pellets in a hard gelatin capsule could mask the bad odour of the drug and hence can improve patient compliance.

\section{CONFLICT OF INTEREST}

The authors confirm that this article content has no conflict of interest.

\section{ACKNOWLEDGEMENTS}

The authors wish to thank MSN Laboratories Limited, Bollaram, India and Ankit Pulps Pvt. Ltd. India that kindly provided the samples of prasugrel hydrochloride and Avicel respectively.

\section{REFERENCES}

[1] Schmidt C, Bodmeier RA. Multiparticulate drug-delivery system based on pellets incorporated into congealable polyethylene glycol carrier materials. Int J Pharm 2001; 216: 9-16.

[2] Pal S, Nagy S, Bozo T, Kocsis B, Devay A. Technological and biopharmaceutical optimization ofnystatin release from a multiparticulate based bioadhesive drug delivery system. Eur J Pharm Sci 2013; 49: 258-64.

[3] Cosijns A, Nizet D, Nikolakakis I, et al. Porous pellets as drug delivery system. Drug Dev Ind Pharm 2009; 35: 655-62.

[4] Varum FJO, Merchant HA, Basit AW. Oral modified-release formulations in motion: The relationship between gastrointestinal transit and drug absorption. Int J Pharm 2010; 395: 26-36.

[5] Lyne CW, Johnston HG. The selection of pelletisers. Powder Technol 1981; 29: 211-6.

[6] Ghebre-Sellassie I, Gordon R, Fawzi MB, Nesbitt RU. Evaluation of a high-speed pelletization process and equipment. Drug Dev Ind Pharm 1985; 11: 1523-41.

[7] Vertommen J, Kinget R. The influence of five selected processing and formulation variables on the particle size, particle size distribution, and friability of pellets produced in a rotary processor. Drug Dev Ind Pharm 1997; 23: 39-46.

[8] Vervaet C, Baert L, Remon JP. Extrusion-Spheronisation: A literature review. Int J Pharm 1995; 116: 131-46.

[9] Sinha VR, Agrawal MK, Kumria R. Influence of Formulation and Excipient Variables on the Pellet Properties Prepared by Extrusion Spheronization. Curr Drug Deliv 2005; 2: 1-8.

[10] Bashaiwoldu AB, Podczeck F, Newton JM. A study on the effect of drying techniques on the mechanical properties of pellets and compacted pellets. Eur J Pharm Sci 2004; 21: 119-29.

[11] Schmidt C, Lindner H, Kleinebudde P. Comparison between a twin-screw extruder and a rotary ring die press. Influence of formulation variables. Eur J Pharm Biopharm 1997; 44: 169-176.

[12] Ghebre-Sellassie I, Pharmaceutical Pelletization Technology. Marcel Dekker: New York, 1989.

[13] Dukic-Ott A, De Beer T, Remon JP, Baeyens W, Foreman P, Vervae C. In-vitro and in-vivo evaluation of enteric-coated starchbased pellets prepared via extrusion/spheronisation. Eur J Pharm Biopharm 2008; 70: 302-12.

[14] Guerra DR, Tcheng JE. Prasugrel: Clinical development and therapeutic application. Adv Ther 2009; 26: 999-1011.

[15] Seo EJ, Lee DU, Kwak JH, Lee SM, Kim YS, Jung YS. Antiplatelet effects of Cyperus rotundus and its component (+)nootkatone. J Ethnopharmacol 2011; 135: 48-54.

[16] Masciaa S, Seiler C, Fitzpatrick S, Wilsona DI. Extrusionspheronisation of microcrystalline cellulose pastes using a nonaqueous liquid binder. Int J Pharm 2010; 389: 1-9. 
[17] Husson I, Leclerc B, Spenlehauer G, Veillard M, Puisieux F, Couarraz G. Influence of size polydispersity on drug release from coated pellets. Int J Pharm 1992; 86: 113-21.

[18] Nora YK, Chew HKC. Effect of powder polydispersity on aerosol generation. J Pharm Pharmaceut Sci 2002; 5: 162-8.

[19] Dash V, Behera SK. Agarwal R, Sinha N. Pelletization technique in drug delivery system. J Curr Pharm Res 2012; 9: 19-25.

[20] Sinha VR, Agrawal MK, Kumria R, Bhinge JR. Influence of operational variables on properties of piroxicam pellets prepared by extrusion-spheronization: A technical note. AAPS PharmSciTech 2007; 8: E1-5.

[21] Kalam MA, Humayun N, Parvez N, et al. Release kinetics of modified pharmaceutical dosage forms: A review. Cont J Pharm Sci 2007; 1: 30-5.

[22] Costa P, Lobo S. Modeling and comparison of dissolution profiles. Eur J Pharm Sci 2001; 13: 123-33.

[23] O'Connor RE, Schwartz JB. Drug release mechanism from a microcrystalline cellulose pellet system. Pharm Res 1993; 10: 35661

Received: December 26, 2014

Revised: October 03, 2015

Accepted: October 27, 2015

(C) Kanwar et al.; Licensee Bentham Open.

This is an open access article licensed under the terms of the (https://creativecommons.org/licenses/by/4.0/legalcode), which permits unrestricted, noncommercial use, distribution and reproduction in any medium, provided the work is properly cited. 